\title{
Rapid tests to assess concentrate feed acceptability by goats
}

\author{
P. MORAND-FEHR, J. HERVIEU, D. LEGENDRE, A. GUTTER, \\ L. DEL TEDESCO
}

\author{
Station de Nutrition et Alimentation (INRA) \\ I.N.A.-P.G. 16, rue Claude-Bernard, 75231 Paris Cedex 05 (France)
}

\begin{abstract}
Several, or all, Alpin or Saanen goats of a flock often refuse partly or totally compound concentrate feeds and need a long time to get adaptated to these feeds.

Rapid tests were developed to assess the acceptability of concentrate feeds for goats and the risk of refusal.

In two experiments (A and B) 8 and 3 compound feeds, respectively were allocated to 10 dairy goats either successively and separately for 4 and 10 days (long allocation test LAT) or several feeds simultaneously, once a day for 3 or 4 min (rapid acceptability test RAT) ; the choice of tested feeds changed every day. LAT and RAT classified feeds in the same order according to their level of intake (interfeed and intergoat correlation of ingested quantities of feeds in LAT and RAT $=0.87$ and 0.93 in experiments $\mathrm{A}$ and $\mathrm{B}$ ).
\end{abstract}

As it was shown that RAT could rapidly predict the responses of goats to more or less palatable feeds, we established the standard experimental conditions for improving the reproductibility of RAT. In an isolated cabin, each goat was simultaneously given 2 feeds, each one distributed in 2 containers ( $200 \mathrm{~g}$ a container) for 2 minutes divided into 4 times $30 \mathrm{~s}$ in order to increase the number of choices. The place of the four containers in the trough was changed at each sequence to neutralize position habits of goats in the choice of containers. Goats used in RAT were selected for their capacity to discriminate feed acceptability and they were accustomed to RAT conditions. When several feeds had to be tested, all possible combinations of 2 feeds were presented to goats, but each goat was used for only one test a day. The acceptability of a feed is defined as the mean quantity ingested by all the goats in all the tests.

To assess the reproducibility of RAT, these experimental conditions were exactly applied in experiment $C$, where 4 feeds were tested in the 14 same goats in 6 trials which were repeated twice : in the first succession $138,98,66,98 \mathrm{~g} /$ goat/test, and then : $134,102,68$ and $98 \mathrm{~g} / \mathrm{goat} /$ test. A good reproducibility of RAT (interfeed correlation $=0.98$ ) was obtained.

Therefore, RAT seems to be useful in rapidly assessing the acceptability of feeds for dairy goats applied in strict standard conditions.

Key words: Goat, acceptability, concentrate, test.

\section{Effect of amount offered on selection and intake of long untreated barley straw by goats}

\author{
E. OWEN, R.A. WAHED, R. ALIMON \\ University of Reading, Department of Agriculture, Earley Gate, Reading RG6 2AT, GB
}

The conventional method of measuring ad libitum intake of roughages involves offering sufficient to ensure that 15 to $20 \%$ is left at the end of the feeding period. Preliminary evidence indicated that selection and hence intake would increase if more roughage was offered. Two experiments were undertaken with individually penned Saanen castrates, ranging in live weight from 15 to $65 \mathrm{~kg}$, fed restricted concentrates (15 g dry matter (DM) per $\mathrm{kg} \mathrm{W}$ W $^{0.5}$ daily) and ad libitum long barley straw. Straw offered and refused was weighed and digestible organic matter in vitro (DOMD) (Tilley and Terry method) was measured in representative samples. In experiment 